\title{
Neuronal Acetylcholine Receptors: Fate of Surface and Internal Pools in Cell Culture
}

\author{
Jes Stollberga and Darwin K. Berg \\ Department of Biology, University of California, San Diego, La Jolla, California 92093
}

Chick ciliary ganglion neurons have nicotinic ACh receptors that mediate synaptic input to the cells. Ultrastructural studies with a monoclonal antibody that recognizes the neuronal ACh receptor have previously shown that, in addition to a predominantly synaptic location for the receptors on the neuron surface in vivo, substantial amounts of intracellular receptor are present as well. Here we report that intracellular receptor and smaller receptor-related components make up at least two-thirds of the total antibody binding sites associated with the ciliary ganglion neurons in cell culture. The intracellular sites for the most part represent integral membrane components that bind to concanavalin A when solubilized, indicating that the components are glycosylated. Sucrose gradient analysis shows that the Intracellular material includes a $10 \mathrm{~S}$ component, likely to represent assembled receptor, along with species sedimenting in the 5-9 S range. Blocking the surface sites with unlabeled antibody and measuring the appearance of the new receptor on the cell surface with radiolabeled antibody indicates that the receptors are inserted into the plasma membrane at a rate equivalent to about $4 \%$ of the total surface receptor per hour. The transit time for newly synthesized receptor to reach the cell surface appears to be 2-3 hr. These observations suggest that about $5 \%$ of the intracellular receptors are transported to the cell surface in culture. The half-life of ACh receptors in the plasma membrane was estimated by 2 different approaches to be about 22 hr. Surface and internal sites respond in a qualitatively similar way to external agents that specifically modulate cholinergic receptors. These studies demonstrate that neuronal ACh receptors display a number of properties similar to muscle receptors in cell culture, including a similar half-life in the plasma membrane and a similar distribution between surface and internal pools. The significance of the large internal pool that can be modulated by extracellular agents but is not destined to be transported to the surface remains to be determined.

Recently, probes have been developed for examining the number and distribution of nicotinic acetylcholine receptors ( $\Lambda$ ChRs) on neurons. One of these is a monoclonal antibody, mAb 35,

Received Aug. 22, 1986; revised Nov. 20, 1986; accepted Dec. 3, 1986.

We thank Dr. Jon Lindstrom for giving us the hybridoma cell line that produces $\mathrm{mAb} 35$, and we thank Dannielle Pellegrin and Alfredo Franco, Jr., for expert technical assistance. Grant support was provided by the National Institutes of Health (NS 12601), the Muscular Dystrophy Association, and the American Heart Association with funds contributed in part by the California Heart Association.

Correspondence should be addressed to Darwin K. Berg, Department of Biology, B-022, University of California, San Diego, La Jolla, CA 92093.

a Present address: Department of Physiology and Biophysics, University of California, Irvine, Irvine, CA 92717.

Copyright (C) 1987 Society for Neuroscience $0270-6474 / 87 / 061809-07 \$ 02.00 / 0$ to the "main immunogenic region" (MIR) of AChR $\alpha$-subunits from muscle and electric organ. MAb 35 cross-reacts with a component on chick ciliary ganglion neurons that has the ultrastructural location, biochemical properties and cholinergic modulation expected for the neuronal AChR (Jacob et al., 1984; Smith et al., 1985, 1986). Antisera raised against a similar component immunopurified from chick brain with mAb 35 (Whiting and Lindstrom, 1986) specifically block the ACh response of ciliary ganglion neurons (Stollberg et al., 1986). Additional confirmation that $\mathrm{mAb} 35$ distinguishes the neuronal $\mathrm{AChR}$ comes from studies with a second probe for neuronal AChRs, an $\alpha$-neurotoxin that reversibly blocks the $\mathrm{AChR}$ function of chick autonomic neurons. The toxin has been called Bgt 3.1 (Ravdin and Berg, 1979; Ravdin et al., 1981), $\kappa$-bungarotoxin (Chiappinelli, 1983), and toxin F (Loring et al., 1984); by electrophoretic and amino acid sequence analyses the 3 toxins are indistinguishable (Loring et al., 1986). Bgt 3.1 binds to a class of sites on ciliary ganglion neurons in culture with the affinity, kinetics, pharmacology, and specificity expected for the neuronal AChR (Halvorsen and Berg, 1986a). Cross-linking studies with a photoaffinity derivative of Bgt 3.1 demonstrate that Bgt 3.1 and $\mathrm{mAb}$ 35 recognize the same neuronal component (Halvorsen and Berg, 1986b, 1987). The AChR identified by both Bgt 3.1 and $\mathrm{mAb} 35$ is clearly distinct from the membrane component of unknown function on the neurons that binds $\alpha$-bungarotoxin (Jacob and Berg, 1983; Smith et al., 1983, 1985; Jacob et al., 1984).

Ultrastructural studies with mAb 35 have demonstrated that the AChR on chick ciliary ganglion neurons has a predominantly synaptic location in vivo (Jacob et al., 1984). A preliminary account of toxin $F$ (Bgt 3.1) binding in the ganglion indicates a similar distribution (Loring et al., 1985). Ultrastructural analysis of mAb 35 binding in saponin-permeabilized embryonic ganglia, however, reveals a substantial number of specific intracellular binding sites as well (Jacob et al., 1986). The sites are associated with organelles known to comprise the biosynthetic and regulatory pathways of integral plasma membrane proteins. We report here studies on the number and fate of intracellular $\mathrm{mAb} 35$ binding sites for ciliary ganglion ncurons in cell culturc and examine the insertion rate and half-life for AChR in the neuronal plasma membrane.

\section{Materials and Methods}

Cell cultures. Dissociated ciliary ganglion cell cultures were prepared from $8 \mathrm{~d}$ chick embryos and grown at $37^{\circ} \mathrm{C}$ in an atmosphere of $5 \%$ $\mathrm{CO}_{2} / 95 \%$ air on a substratum of collagen and lysed fibroblasts as previously described (Nishi and Berg, 1981). Cultures contained about $1.4 \times 10^{4}$ neurons $/ 16 \mathrm{~mm}$ well (or $7 \times 10^{4}$ neurons $/ 35 \mathrm{~mm}$ dish for sucrose gradient experiments) and were grown in a culture medium consisting of Eagle's minimal essential medium containing $10 \%$ (vol/ 
vol) heat-inactivated horse serum, 50 units $/ \mathrm{ml}$ penicillin, $50 \mu \mathrm{g} / \mathrm{ml}$ streptomycin, and 3\% (vol/vol) embryonic eye extract (Nishi and Berg, 1981). Culture medium was replaced at 2-3 d intervals and cultures were taken for experiments at $4 \mathrm{~d}$ unless otherwise indicated.

$M A b 35$ binding. Binding of mAb 35 to the surface of ciliary ganglion neurons in culture was measured by first rinsing the cultures 2 times with a solution containing $123 \mathrm{~mm} \mathrm{NaCl}, 5.4 \mathrm{~mm} \mathrm{KCl}, 11 \mathrm{~mm} \mathrm{NaPO}_{4}$ pH 7.4, $0.9 \mathrm{~mm} \mathrm{CaCl}_{2}, 0.4 \mathrm{~mm} \mathrm{MgSO} 4,0.5 \%$ phenol red, and $2 \mathrm{mg} / \mathrm{ml}$ BSA (incubation buffer). The cultures then received incubation buffer containing $5 \mathrm{~nm}{ }^{125} \mathrm{I}-\mathrm{mAb} 35$, and after $30 \mathrm{~min}$ at room temperature were rinsed 5 times with $1 \mathrm{ml}$ aliquots of incubation buffer, scraped in $0.5 \mathrm{ml}$ of $1.0 \mathrm{~N} \mathrm{NaOH}$, and analyzed for bound radioactivity with a Tracor analytic model 1191 gamma counter at a counting efficiency of $75 \%$. Nonspecific binding, determined by including a 20 -fold excess of unlabeled $\mathrm{mAb} 35$ in the labeling reaction, usually constituted $20-30 \%$ of total binding and was subtracted in all cases to yield specific binding. Previous studies have shown that the saturable mAb 35 binding determined in this way is specific (Smith et al., 1985, 1986).

Total specific binding of $\mathrm{mAb} 35$ to neuronal sites in culture, including both surface and internal sites, was determined by rinsing the cultures twice with incubation buffer and then scraping and homogenizing them in $20 \mu \mathrm{l}$ of solution containing $50 \mathrm{~mm} \mathrm{NaCl}, 10 \mathrm{~mm} \mathrm{NaPO}, \mathrm{pH} 7.4$, and $0.5 \%$ Triton X-100 (homogenization buffer, $\mathrm{HB}$ ). Extracts were pooled and assayed in $50 \mu \mathrm{l}$ aliquots for specific ${ }^{125} \mathrm{I}-\mathrm{mAb} 35$ binding, using small DEAE-cellulose columns to separate bound and free $\mathrm{mAb}$ 35 as previously described (Smith et al., 1985). The following modifications were made in the assay procedure: Reaction volumes contained the equivalent of 2-3 culture wells; binding was carried out for $30 \mathrm{~min}$; fetal calf serum at $1: 16$ dilution replaced the rat serum previously used to decrease nonspecific binding to column material; the reaction was terminated by dilution with $0.60 \mathrm{ml} \mathrm{HB}$; aliquots were assayed in triplicate on individual DEAE-cellulose columns. Nonspecific binding was determined as described above and was subtracted in all cases to yield specific binding. The efficiency of the DEAE column assay was assessed by labeling surface sites in culture with ${ }^{125} \mathrm{I}-\mathrm{mAb} 35$, rinsing the cultures, homogenizing them, and determining the proportion of the specifically bound $\mathrm{mAb} 35$ retained by the column. A mean value of $64 \%$ was obtained from repeated trials. In all cases the total site values were corrected for the efficiency of the DEAE column assay and for the efficiency of solubilization in IIB versus $1 \mathrm{~N} \mathrm{NaOH}$. The number of internal sites for the neurons in culture was calculated as the difference between the total sites measured in extracts and the surface sites measured with intact cells. In some cases, surface and total sites were determined with the same cultures, first measuring surface sites by scraping into $\mathrm{HB}$ instead of $\mathrm{NaOH}$ for gamma counting and then incubating the extracts with additional ${ }^{125} \mathrm{I}-\mathrm{mAb} 35$ and measuring total sites with the DEAE column assay as described above.

Solubilization. Solubilization of the mAb 35 binding component was examined by scraping and homogenizing 24 cultures in a final volume of $0.50 \mathrm{ml} \mathrm{HB}$ without Triton X-100 and then dividing the homogenate into 5 aliquots. One aliquot received Triton X-100 to yield a final concentration of $0.5 \%$ and, after being centrifuged $5 \mathrm{~min}$ at $4^{\circ} \mathrm{C}$ in a microfuge to remove particulate matter, was assayed for total soluble $\mathrm{mAb} 35$ binding sites with the DEAE column assay. Two other aliquots were incubated with or without $1 \mathrm{M} \mathrm{NaCl}$ for $15 \mathrm{~min}$ at room temperature and then centrifuged $5 \mathrm{~min}$ at $4^{\circ} \mathrm{C}$ in a microfuge to collect membrane fragments. The fragments were then solubilized with Triton X-100 and assayed with the DEAE column procedure to determine the proportion of associated $\mathrm{mAb} 35$ binding sites. The 2 remaining aliquots were solubilized with Triton X-100 as described above and incubated with concanavalin A coupled to Sepharose beads in the presence or absence of $1 \mathrm{M} \alpha$-methyl-mannoside, $5 \mathrm{~mm}$ EDTA, and $5 \mathrm{~mm}$ EGTA for $30 \mathrm{~min}$ at $4^{\circ} \mathrm{C}$. After centrifugation for $2 \mathrm{~min}$ in a microfuge, the supernatant fractions were assayed for $\mathrm{mAb} 35$ binding sites to determine the proportion not adsorbed by the concanavalin A beads.

Sucrose gradient centrifugation. Membrane fragments were collected from ten $35 \mathrm{~mm}$ dish $7 \mathrm{~d}$ cultures by scraping the cultures into $1.0 \mathrm{ml}$ HB without detergent and then centrifuging the homogenate $30 \mathrm{~min}$ at $4^{\circ} \mathrm{C}$ in a microfuge. The pellet was solubilized by trituration in $0.30 \mathrm{ml}$ $\mathrm{HB}$ and centrifuged $5 \mathrm{~min}$ at $4^{\circ} \mathrm{C}$ in a microfuge to remove particulate debris. An aliquot $(0.24 \mathrm{ml})$ was layered onto a $4.8 \mathrm{ml}$ linear gradient of $5-20 \%$ sucrose in HB. Centrifugation was carried out at $60,000 \mathrm{rpm}$ for $60 \mathrm{~min}$ at $4^{\circ} \mathrm{C}$ in a Beckman Vti 65 rotor. Gradient fractions $(0.3$ $\mathrm{ml}$ ) were collected and assayed for $\mathrm{mAb} 35$ binding using the DEAE column assay. The sedimentation markers catalase (11.3 S) and bacterial alkaline phosphatase $(6.1 \mathrm{~S})$ were included in the same tube with the sample. Recoveries were determined by comparing the total number of sites in gradient fractions to those assayed at the same time in an aliquot of the solubilized starting material.

Materials. White leghorn chick embryos were obtained locally and maintained at $39^{\circ} \mathrm{C}$ in a humidified incubator. Tissue extracts and culture media were prepared as previously described (Nishi and Berg, 1981). Culture media components were obtained from Grand Island Biological Co. except for horse serum, which was obtained from Whitakker M.A. Bioproducts. Na ${ }^{125}$ I was obtained from Amersham. The hybridoma cell line secreting $\mathrm{mAb} 35$ was generously provided by Jon Lindstrom of the Salk Institutc. MAb 35 was purified and radioiodinated to specific activities of $2-3 \times 10^{18} \mathrm{cpm} / \mathrm{mol}$ as previously described (Smith et al., 1985). Bungarus multicinctus venom, purchased from Miami Serpentarium, was used for the purification of Bgt 3.1 as previously described (Ravdin et al., 1981). Concanavalin A coupled to Sepharose 4B, $\alpha$-methyl-mannoside, cycloheximide, tunicamycin, catalase, and bacterial alkaline phosphatase were purchased from Sigma.

\section{Results}

\section{Intracellular binding sites}

The number of intracellular mAb 35 binding sites in ciliary ganglion neurons was determined in cell culture by comparing the number of sites present on intact cells with those present in culture homogenates. The difference between the total specific sites and the surface specific sites was taken to represent intracellular AChR or AChR-related material. At every time examined during a 1 week period in culture, at least two-thirds of the total specific mAb 35 binding sites associated with the neurons were present in an internal pool by this criterion (Fig. 1). The internal sites clearly represented integral membrane components since essentially all of the mAb 35 binding sites detected in detergent extracts of culture homogenates were originally associated with membrane fragments and could not be eluted from the fragments by high salt concentrations in the absence of detergent (Table 1). More than half of the intracellular sites represented glycosylated protein since most of the solubilized binding material was specifically adsorbed by concanavalin $\mathrm{A}$ (Table 1), as has been demonstrated for solubilized mAb 35 binding components from freshly dissected ciliary ganglia (Smith et al., 1985). Sucrose gradient sedimentation of detergent-solubilized culture homogenates indicated that a large proportion of the total sites sedimented at $10 \mathrm{~S}$ (Fig. 2), as seen for mAb 35 binding sites from ciliary ganglia (Smith et al., 1985). These data suggest that at least a portion of the intracellular binding material is likely to represent assembled receptor. Substantial amlounts of binding material, however, also sedimented at slower rates, raising the possibility that some of the intracellular mAb 35 binding sites may represent unassembled precursors or byproducts of receptor degradation.

\section{Insertion into the plasma membrane}

To examine the fate of the internal sites, we first determined the rate at which new sites are inserted into the plasma membrane of the neurons in culture. The approach depended on blocking existing mAb 35 surface sites with unlabeled antibody and then monitoring the appearance of new sites with ${ }^{125} \mathrm{I}-\mathrm{mAb}$ 35 . It was necessary to correct the results for the reappearance of preexisting sites that were exposed by dissociation of the unlabeled antibody. To determine the rate of mAb 35 dissociation, sites on sister cultures were blocked with $\mathrm{mAb} 35$ and then maintained in cycloheximide to inhibit protein synthesis and prevent the appearance of new sitcs. The concentration of cycloheximide used $(10 \mu \mathrm{g} / \mathrm{ml})$ blocked protein synthesis by great- 


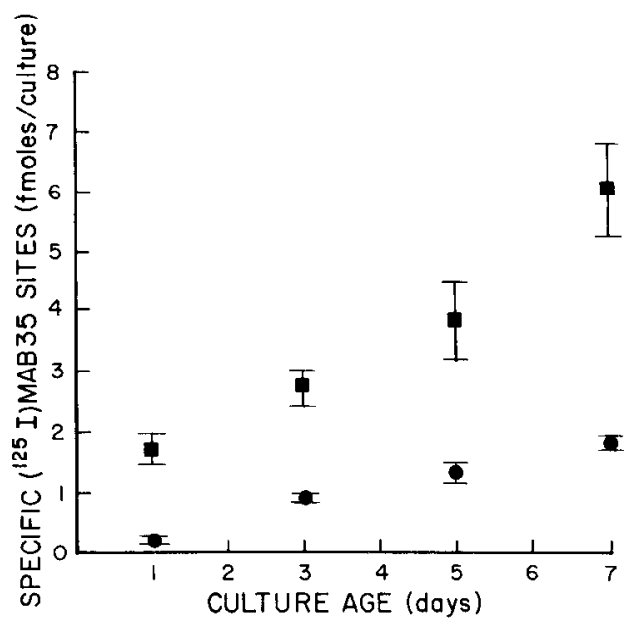

Figure 1. Increase in the number of surface and total mAb 35 binding sites with time in culture. Cultures of ciliary ganglion neurons were assayed at the indicated times for the amount of specific ${ }^{125} \mathrm{I}-\mathrm{mAb} 35$ binding to the surface of the cells (circles) and to total sites in detergent extracts (squares). The internal sites, calculated as the difference between the total sites and surface sites, represented at least two-thirds of the total sites at all times tested. Each point indicates the mean $\pm \mathrm{SE}$ for 2-4 sets of cultures, with a set consisting of 3 cultures for each determination.

er than $95 \%$ as monitored by radiolabeled amino acid incorporation into acid-precipitable material (Stollberg, 1985). When the rates of appearance for "new" mAb 35 binding sites were compared in cultures maintained with and without cycloheximide, it was clear that the rates began to diverge after about 2 hr (Fig. 3). For an additional $6 \mathrm{hr}$ "new" sites appeared at a small but constant rate in cultures maintained in cycloheximide. Since receptor synthesis was blocked by the cycloheximide, these "new" sites were interpreted to represent dissociation of unlabeled $\mathrm{mAb} 35$ from preexisting sites on the surface of the neurons. An even faster rate of dissociation was measurcd for ${ }^{125} \mathrm{I}-$ mAb 35 bound to neurons in culture (data not shown), most likely because the receptor has a lower affinity for the radioiodinated antibody. When the data in Figure 3 were corrected for

Table 1. Solubilization and concanavalin A adsorption of mAb 35 binding components from ciliary ganglion neuron cultures

\begin{tabular}{lc} 
Fraction & $\begin{array}{l}\text { mAb } 35 \\
\text { Binding } \\
(\%)\end{array}$ \\
\hline Control & $100 \pm 6$ \\
Membrane fragments & $96 \pm 11$ \\
Salt-extracted membranes & $93 \pm 9$ \\
Concanavalin A adsorbed extract & $25 \pm 5$ \\
Concanavalin A $/ \alpha$-MM adsorbed extract & $77 \pm 9$
\end{tabular}

Culture homogenates were either solubilized in $\mathrm{HB}$ and assayed for ${ }^{125} \mathrm{I}-\mathrm{mAb} 35$ binding sites (control) or were centrifuged to collect membrane fragments that were then either detergent-solubilized and assayed for sites (membrane fragments) or extracted with $1 \mathrm{~m} \mathrm{NaCl}$, solubilized, and assayed for sites (salt-extracted membranes). Solubilized culture homogenates were also used to determine the proportion of binding sites that remained after the extracts were adsorbed with concanavalin A conjugated to Sepharose $4 \mathrm{~B}$ or adsorbed with concanavalin A in the presence of $\alpha$-methylmannoside $(\alpha-\mathrm{MM})$. The results are expressed as a percentage of controls and represent the mean $\pm S E$ of 2 experiments, where each experiment involved 3 cultures per determination.

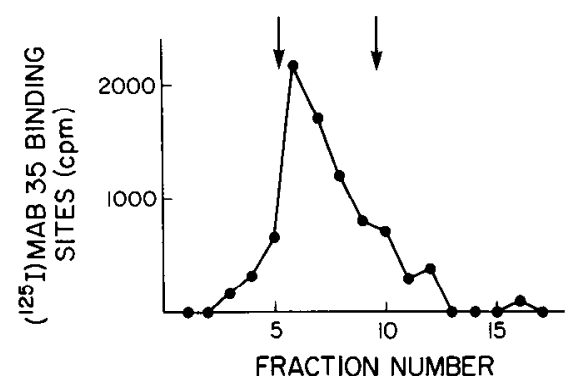

Figure 2. Sucrose-gradient sedimentation of mAb 35 binding component in detergent extracts prepared from cultures of ciliary ganglion neurons. A detergent extract of 7-d-old ciliary ganglion cell cultures was centrifuged through a sucrose gradient; fractions were collected and measured for specific ${ }^{125} \mathrm{I}-\mathrm{mAb} 35$ binding in duplicate DEAE column assays. Total recovery of $\mathrm{mAb} 35$ binding sites from the gradient was $66 \%$. The arrows indicate the positions from left to right of catalase $(11.3 \mathrm{~S})$ and bacterial alkaline phosphatase $(6.1 \mathrm{~S})$, included in the gradient for calibration of sedimentation. Similar results were obtained in a second experiment.

appearance of sites through dissociation of unlabeled antibody, the results shown in Figure 4 were obtained. New sites appeared in the neuronal plasma membrane at a constant rate for the 8 hr period examined (Fig. 4A). For cultures maintained in cycloheximide, a similar rate of appearance was obtained for the first $2 \mathrm{hr}$, and then appearance of new sites was blocked (Fig. $4 B)$. These results suggest a $2 \mathrm{hr}$ lag between synthesis and insertion into the cell surface.

At $4 \mathrm{~d}$ in culture the mean insertion rate of $\mathrm{mAb} 35$ binding sites into the plasma membrane is equivalent to about $4 \%$ of the existing surface sites per hour. This value was obtained from experiments similar to those described above except that the appearance of new sites was determined for 2 sequential $2 \mathrm{hr}$ periods (Table 2). Corrections for reappearance of preexisting sites due to $\mathrm{mAb}$ dissociation were calculated from sister cultures maintained in cycloheximide for $4 \mathrm{hr}$ and then assayed for appearance of "new" mAb 35 binding sites in the same 2 sequential $2 \mathrm{hr}$ periods in the continued presence of cycloheximide.

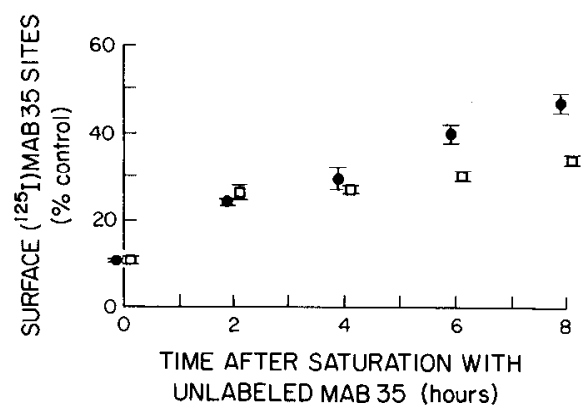

Figure 3. Appearance of $\mathrm{mAb} 35$ binding sites on the neuronal surface after occupation of existing sites with $\mathrm{mAb} 35$. Surface sites on neurons were saturated with $20 \mathrm{nM} \mathrm{mAb} 35$ for $1 \mathrm{hr}$ at $37^{\circ} \mathrm{C}$, rinsed, and then incubated with (open squares) or without (filled circles) $10 \mu \mathrm{g} / \mathrm{ml} \mathrm{cy-}$ cloheximide for the indicated times, and assayed for the number of specific surface sites with ${ }^{129} \mathrm{I}-\mathrm{mAb} 35$. The rates of receptor appearance diverge after approximately $2 \mathrm{hr}$. The binding detected at 0 time reflects incomplete saturation of the sites by unlabeled $\mathrm{mAb} 35$. Each point indicates the mean $\pm \mathrm{SE}$ for 2 sets of cultures, with a set consisting of 3 cultures for each determination. 


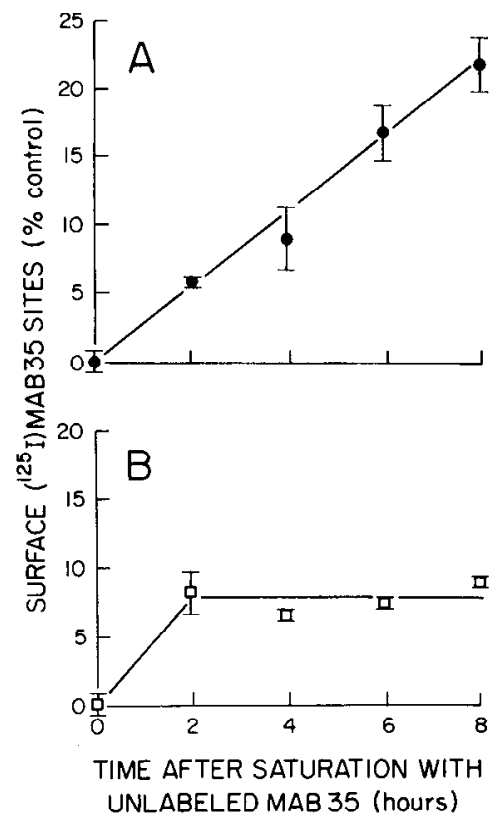

Figure 4. Corrected rates for appearance of new mAb 35 binding sites on the neuronal surface. The data from Figure 3 were corrected in 2 ways and replotted here. The amount of ${ }^{125} \mathrm{I}-\mathrm{mAb} 35$ binding obtained at 0 time was interpreted as unoccupied existing sites and was subtracted accordingly. The average rate of increase in ${ }^{125} \mathrm{I}-\mathrm{mn} \mathrm{Ab} 35$ binding obtained at late times in cycloheximide (after $2 \mathrm{hr}$ ) was taken to represent dissociation of unlabeled mAb 35 from preexisting sites and was also subtracted. $A$, Cultures in normal medium. $B$, Cultures in medium supplemented with $10 \mu \mathrm{g} / \mathrm{ml}$ cycloheximide. Curves were fit by eye. Values are expressed as the percentage of total surface sites in cultures prior to incubation with unlabeled mAb 35 .

\section{Turnover rates}

Previous results measuring the net accumulation of $\mathrm{mAb} 35$ binding sites on ciliary ganglion neurons in culture (Smith et al., 1986) indicated a rate of accumulation equivalent to about $1 \%$ of the surface sites per hour in $4 \mathrm{~d}$ cultures (Table 3 ). Subtracting the rate for net accumulation from the rate determined here for insertion into the surface membrane yielded a rate of $3 \% / \mathrm{hr}$ for loss of sites from the cell surface. Assuming a homogeneous population of surface $\mathrm{mAb} 35$ binding components

Table 2. Rate of appearance of new sites on the neuronal surface

Appearance of $\mathrm{mAb} 35$ binding sites

Cultures of ciliary ganglion neurons were incubated with mAb 35 to block specific binding sites as described in Figure 3 and then were assayed for ${ }^{125} \mathrm{I}-\mathrm{mAb} 35$ binding at 0,2 , or $4 \mathrm{hr}$. Re-exposure of preexisting sites through $\mathrm{mAb}$ dissociation was evaluated by measuring ${ }^{125} \mathrm{I}-\mathrm{mAb}$ binding at the same intervals in sister cultures that had been maintained in $10 \mu \mathrm{g} / \mathrm{ml}$ cycloheximide, starting $4 \mathrm{hr}$ before the blockade with mAb 35. Binding in the cycloheximide-treated cultures was subtracted from the values obtained for untreated cultures to yield the number of new sites that appeared during the indicated intervals. 0-2 hr: difference in ${ }^{225} \mathrm{I}-$ $\mathrm{mAb} 35$ binding for cultures 0 and $2 \mathrm{hr}$ after mAb 35 blockade; 2-4 hr: difference in binding for cultures 2 and $4 \mathrm{hr}$ after blockade; per hr: data averaged and expressed per hour. Values are expressed as a percentage of the surface binding observed in control cultures at time 0 without mAb 35 blockade and represent the mean of 3 cultures per determination in each experiment.
Table 3. Parameters for the appearance and turnover of mAb 35 binding sites on ciliary ganglion neurons in culture

\begin{tabular}{lc} 
Parameter & Value \\
\hline Transport time & $2-3 \mathrm{hr}$ \\
Insertion rate & $4.1 \pm 0.2 \% / \mathrm{hr}$ \\
Accumulation rate & $0.97 \pm 0.05 \% / \mathrm{hr}$ \\
Turnover rate & $3.1 \pm 0.2 \% / \mathrm{hr}$ \\
Half-life & $22 \pm 2 \mathrm{hr}$
\end{tabular}

The time for newly synthesized mAb 35 binding component to appear on the cell surface (transport time) was taken to be the time during which mAb 35 binding sites appeared on the cell surface at equal rates in cultures incubated with and without cycloheximide. The rate of insertion was calculated as the rate of site appearance on neurons after corrections were made for dissociation of unlabeled antibody from preexisting surface sites. The rate of site accumulation was calculated from previous data (Smith et al., 1986). The rate of turnover was calculated as the difference between the rates of insertion and accumulation. All rates are expressed as a percentage of the surface sites present in untreated cultures at the time of the experiments. The half-life of the binding component on the neuronal surface was calculated from the turnover rate, assuming a homogeneous population in this respect.

with respect to metabolic stability, this rate of loss corresponds to a half-life of $22 \pm 2 \mathrm{hr}$ for the surface component (Table 3 ).

An alternative method for determining turnover rate would be to measure the loss of sites from the cell surface directly. We used tunicamycin to block the insertion of new sites into the plasma membrane so that loss of preexisting sites from the cell surface could then be measured. Tunicamycin inhibits asparagine-linked glycosylation and as a result prevents insertion of proteins into the plasma membrane. Tunicamycin blocks the appearance of nicotinic AChRs on skeletal myotubes (Merlie et al., 1982) and muscarinic AChRs on neuroblastoma cells (Liles and Nathanson, 1986). It does not appear to alter the rate of receptor degradation (Liles and Nathanson, 1986). In cultures of ciliary ganglion neurons, $0.8 \mu \mathrm{g} / \mathrm{ml}$ tunicamycin blocked over $90 \%$ of glycosylation, as monitored by incorporation of ${ }^{3} \mathrm{H}$ mannose into acid-precipitable material (data not shown). The disappearance of $\mathrm{mAb} 35$ binding sites from the surface of ciliary ganglion neurons incubated in $0.8-1.0 \mu \mathrm{g} / \mathrm{ml}$ tunicamycin followed a single-exponential rate of decay after an initial $2-3 \mathrm{hr}$ lag (Fig. 5). The half-life of the mAb 35 binding component on the neuronal surface, calculated from the rate of receptor loss in the presence of tunicamycin, was $23 \mathrm{hr}$. This value is in close agreement with the half-life of $22 \mathrm{hr}$ calculated above from the rate measurements for insertion and net accumulation of the binding component in the surface membrane.

\section{Modulation of internal sites}

A very small proportion of the intracellular sites detected by $\mathrm{mAb} 35$ binding appcars destined to reach the cell surface of ciliary ganglion neurons in culture. This conclusion follows from the 2-3 hr lag time estimated for expression on the surface of newly synthesized binding component, from the value of $4 \%$ / $\mathrm{hr}$ for the rate of insertion into surface membrane, and from the size of the intracellular pool (see Discussion). To identify a possible link between surface component and the large amount of intracellular material not destined for surface expression, we examined the response of internal sites to conditions known to modulate the number of surface sites on the neurons. Chronic exposure of cells to the cholinergic agonist carbachol has been shown to decrease the number of $\mathrm{mAb} 35$ binding sites on ciliary ganglion neurons in culture (Smith et al., 1986), as it does the number of AChRs on skeletal myotubes (Gardner and Fam- 


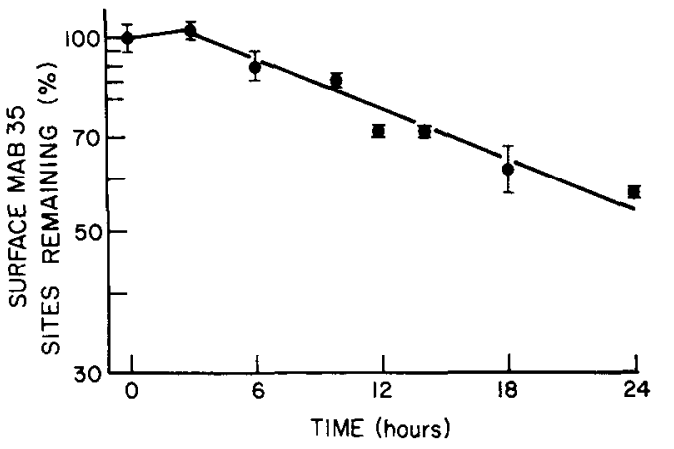

Figure 5. Disappearance of mAb 35 binding sites from the neuronal surface in tunicamycin. Cultures of ciliary ganglion neurons were incubated in $0.8-1.0 \mu \mathrm{g} / \mathrm{ml}$ tunicamycin and assayed for ${ }^{125} \mathrm{I}-\mathrm{mAb} 35$ binding to intact cells at the indicated times. Values represent the mean \pm SE of results from 3 experiments, with each experiment involving 3 cultures per determination. From the rate at which sites accumulate on the neurons in culture (Smith et al., 1986), the number of surface sites, $S$, measured here should increase by $1 \% / \mathrm{hr}$ for some latency period, $L$, until the tunicamycin blockade is established. Subsequently, the value of $S$ should decline according to an exponential rate of decay, $R$ (assuming a homogeneous population of sites). This process is described as a function of time, $t$, by the equations (1) $S=S_{0}+0.01 t$, for $t<L$, and (2) $S=\left(S_{0}+0.01 L\right) \exp [R(t-L)]$, for $t \geq L$, where $S_{0}=S$ at $t=$ 0 . $L$ and $R$, calculated from the data by least-squares linear-Taylor differential-correction, were $2.7 \mathrm{hr}$ and $-0.031 / \mathrm{hr}$, respectively. The value of $R$ corresponds to a half-life of $22.6 \mathrm{hr}$ for sites in the surface membrane. This solution accounts for $95 \%$ of the data variance, corroborating the expectations of a latency period and a single-exponential rate of decay for the surface sites.

brough, 1979). Carbachol treatment decreases the number of internal sites to the same extent as surface sites on the neurons (Table 4). Chronic exposure to Bgt 3.1, an $\alpha$-neurotoxin that binds to AChRs on ciliary ganglion neurons in culture (Halvorscn and Berg, 1986a), has been shown to decrease the number of surface sites on the neurons (Smith et al., 1986). Incubation with Bgt 3.1 also decreases the number of internal sites, but to a smaller extent (Table 4). Ciliary ganglion neurons grown in culture medium containing $25 \mathrm{mM} \mathrm{K}^{+}$were also examined because this growth condition results in a large decrease in neuronal $\mathrm{ACh}$ sensitivity with no decrease in numbers of mAb 35 binding sites (Smith et al., 1986; Margiotta et al., 1987). This represents the one clear-cut discrepancy between changes in the 2 parameters. Elevated $\mathrm{K}^{+}$concentrations produced small increases in both the number of surface sites and the number of internal sites associated with the neurons (Table 4). Overall, the modulation studies indicate qualitatively similar changes in numbers of surface and internal sites, though modulation of internal sites appears less extensive in one instance.

\section{Discussion}

Substantial evidence indicates that mAb 35 binding sites on ciliary ganglion neurons represent nicotinic AChRs (Jacob et al., 1984, 1986; Smith et al., 1985, 1986; Halvorsen and Berg, 1986a, b, 1987; Stollberg et al., 1986). The finding that the neurons also have large numbers of intracellular mAb 35 binding sites is unexpected in view of the fact that intracellular AChRs have no obvious function. The intracellular location of the sites was inferred from their inaccessibility to antibody when intact cells in culture were incubated with ${ }^{125} \mathrm{I}-\mathrm{mAb} 35$. Neuron cell bodies and processes were fully exposed in the relatively sparse dissociated cell cultures used here, and few non-neuronal
Table 4. Modulation of surface and internal mAb 35 binding sites

\begin{tabular}{lcc} 
Treatment & $\begin{array}{l}\text { Surface sites } \\
(\mathbf{\% )}\end{array}$ & \multicolumn{1}{l}{$\begin{array}{l}\text { Internal sites } \\
(\%)\end{array}$} \\
\hline Control & $100 \pm 5$ & $100 \pm 6$ \\
Carbachol & $78 \pm 3$ & $82 \pm 4$ \\
Bgt 3.1 & $28+1$ & $82 \pm 3$ \\
$\mathrm{~K}^{+}$ & $120 \pm 1$ & $143 \pm 22$
\end{tabular}

Cultures of ciliary ganglion neurons were grown for $1 \mathrm{~d}$ and then supplied with culture medium containing no additional supplements (control), $1 \mathrm{~mm}$ carbachol,

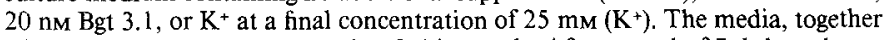
with supplements, were changed at $2 \mathrm{~d}$ intervals. After a total of $7 \mathrm{~d}$ the cultures were assayed for surface and total ${ }^{125} \mathrm{I}-\mathrm{mAb} 35$ binding sites. Values are expressed as a percentage of the binding obtained in control cultures and represent the mean $\pm \mathrm{SE}$ for 2 experiments where each experiment involved 3 cultures per determination. All values were significantly different from controls by Student's $t$ test $(p<0.05)$.

cells were present (Nishi and Berg, 1979) to impede access of the antibodies. Previous ultrastructural studies on saponin-pcrmeabilized ciliary ganglia revealed large numbers of intracellular binding sites for $\mathrm{mAb} 35$ and indicated that the sites were associated with organelles known to be involved in the synthesis, processing, and transport of integral membrane proteins (Jacob et al., 1986). The present studies demonstrate that the intracellular binding sites represent predominantly integral membrane components that are glycosylated and bind to concanavalin $A$, as appears to be the case for AChRs on the surface of the neurons (Messing et al., 1984; Smith et al., 1985). Sucrosegradient analysis reveals a slightly larger proportion of the total $\mathrm{mAb} 35$ binding material from cell cultures sedimenting in the range of 5-9 $\mathrm{S}$ than is true for material from freshly dissected ganglia (Smith et al., 1985). In both cases, however, a substantial proportion of the mAb 35 binding sites sediment as a $10 \mathrm{~S}$ species, a size likely to represent fully assembled AChR (Changeux et al., 1984; Smith ct al., 1986). Largc intraccllular pools have been identified for nicotinic $\mathrm{AChRs}$ of chick and rat skeletal muscle (Devreotes et al., 1977; Merlie and Lindstrom, 1983; Merlie, 1984; Pestronk, 1985) and for voltage-dependent sodium channels in rat brain (Schmidt et al., 1985). Part of the intracellular pool of muscle AChRs has been shown to represent precursors not fully assembled into mature AChRs (Merlie and Lindstrom, 1983; Carlin et al., 1986). The slowly sedimenting material detected by mAb 35 binding in culture homogenates is likely to be AChR-related protein, but it is presently unclear whether the material represents precursor components, degradation products, or defective receptor species.

Only a small fraction of the internal sites in ciliary ganglion neurons appears to be transported to the cell surface in culture. Appearance of the sites on the surface was found to occur at a rate equivalent to $4 \%$ of the surface sites per hour or about $2 \%$ of the internal sitcs per hour. Given a transit time of 2-3 hr for transport of the newly synthesized receptor to the cell surface, one obtains an estimate of about $5 \%$ for the proportion of internal sites that are eventually expressed on the cell surface.

The rate of insertion for AChRs (defined by mAb 35 binding) into the surface membrane was determined indirectly because it has not yet proved possible to label the AChRs of ciliary ganglion neurons metabolically (Stollberg, 1985) and follow their fate with pulse-chase experiments as was done for muscle AChRs (Devreotes et al., 1977; Gardner and Fambrough, 1979; Merlie, 1984). Two aspects of the present experimental approach require comment. The first concerns the use of mAb 35 to block existing 
sites on the neurons so that the appearance of new sites could be detected subsequently. It is possible that antibody bound to surface sites perturbed the rate of AChR insertion into the surface membrane in some manner. This seems unlikely to be a major effect since few treatments alter the insertion rate of $\mathrm{AChR}$ into muscle surface membrane. $\alpha$-Bungarotoxin and $d$-tubocurarine have no effect on the rate of muscle AChR insertion, while carbachol reduces the rate by about 10\% (Gardner and Fambrough, 1979). Moreover, myasthenic sera, which are known to contain a preponderance of antibodies to the MIR of muscle AChR (Tzartos et al., 1982), have no significant effect on the rate of synthesis and insertion of AChRs into the plasma membrane of rat myotubes in culture (Drachman et al., 1978). The second concern involves the use of cycloheximide in control experiments to block the appearance of new receptor so that the rate of $\mathrm{mAb} 35$ dissociating from old receptors could be determined. It is possible that cycloheximide treatment alters receptor processing in some additional manner, resulting in overestimates of $\mathrm{mAb}$ dissociation. Omitting the correction entirely, however, would increase the rate of insertion only by half. Neither consideration is likely to alter the basic finding that only a small proportion of the intracellular $\mathrm{mAb} 35$ binding sites is transported to the cell surface in culture.

A substantial fraction of intracellular AChRs in muscle are not transported to the cell surface (Devreotes et al., 1977; Fambrough and Devreotes, 1978; Merlie and Lindstrom, 1983; Merlie, 1984; Pestronk, 1985). Under some culture conditions nearly all of the muscle AChRs synthesized are confined to an intracellular pool; the receptor is ultimately degraded without being transported to the surface (Olson et al., 1983). The significance of intracellular AChR populations that fail to reach the surface is unknown.

The measured rates for appearance and accumulation of AChRs on the neuronal surface led to an estimate of $22 \mathrm{hr}$ for the half-life of the receptor in the plasma membrane. A value of $23 \mathrm{hr}$ was obtained for the half-life when loss of receptor from the surface was measured directly, using tunicamycin to block the appearance of new receptors on the cell surface. The latency of 2-3 hr obtained for the tunicamycin effect is equivalent to the $2-3 \mathrm{hr}$ transit time estimated for insertion of newly synthesized receptor into the neuronal surface membrane. A similar lag was found for the appearance of newly synthesized muscle AChRs on the cell surface, using metabolic labeling to follow receptor fate (Devreotes et al., 1977; Gardner and Fambrough, 1979). The agreement in values obtained for the $2 \mathrm{ap}-$ proaches used with ciliary ganglion neurons provides reassurance that the findings are not in serious error. An alternative method for blocking insertion of new sites would have been to inhibit protein synthesis with cycloheximide. Cycloheximide has been shown to alter the turnover rates of membrane protcins, however (Reed et al., 1981), and did introduce biphasic kinetics into the rate of receptor loss from the surface of the neurons in culture (Stollberg, 1985). Accordingly, cycloheximide blockade of receptor synthesis was considered unreliable as a means for examining receptor turnover.

The values obtained here for the half-life of AChRs on the surface of chick ciliary ganglion neurons in culture are very similar to values reported previously for the AChR half-life on the surface of chick muscle cells in culture (Devreotes and Fambrough, 1975; Gardner and Fambrough, 1979). They are about 2 -fold greater than the half-life reported for the $\alpha$-bungarotoxin binding component on the surface of chick sympathetic neurons in culture (Carbonetto and Fambrough, 1979). The studies on muscle and sympathetic neurons employed metabolic labeling techniques to examine turnover. Similar techniques need to be applied to the neuronal $\mathrm{AChR}$ when an amenable neuronal system is established.

The modulation studies demonstrate that a portion of the internal mAb 35 binding sites can be regulated by the same conditions that regulate surface receptors. In view of the very small fraction of internal sites destined for expression on the cell surface, the results suggest that the regulatory conditions also influence some receptors confined to intracellular locations. If externally applicd Bgt 3.1 and carbachol act only at the cell surface, the comodulation implies a regulatory coupling between surface and internal populations.

\section{References}

Carbonetto, S., and D. M. Fambrough (1979) Synthesis, insertion into the plasma membrane and turnover of $\alpha$-bungarotoxin receptors in chick sympathetic neurons. J. Cell Biol. 81: 555-569.

Carlin, B. E., J. C. Lawrence, Jr., J. M. Lindstrom, and J. P. Merlie (1986) An acetylcholine receptor precursor $\alpha$ subunit that binds $\alpha$-bungarotoxin but not $d$-tubocurare. Proc. Natl. Acad. Sci. USA 83: 498-502.

Changeux, J.-P., A. Devillers-Thiery, and P. Chemoulli (1984) Acetylcholine receptor: An allosteric protein. Science 225: 1335-1345.

Chiappinelli, V. (1983) Kappa-bungarotoxin: A probe for the neuronal nicotinic receptor in the avian ciliary ganglion. Brain Res. 277: 9-21.

Devreotes, P. N., and D. M. Fambrough (1975) Acetylcholine receptor turnover in membranes of developing muscle fibers. J. Cell Biol. 65 : 335-358.

Devreotes, P. N., J. M. Gardner, and D. M. Fambrough (1977) Kinetics of biosynthesis of acetylcholine receptor and subsequent incorporation into plasma membrane of cultured chick skeletal muscle. Cell 10: 365-373.

Drachman, D. B., C. W. Angus, R. N. Adams, and I. Kao (1978) Effect of myasthenic patients' immunoglobulin on acetylcholine receptor turnover: Selectivity of degradation process. Proc. Natl. Acad. Sci. USA 75: 3422-3426.

Fambrough, D. M., and P. N. Devreotes (1978) Newly synthesized acetylcholine receptors are located in the Golgi apparatus. J. Cell Biol. 76: $237-244$.

Gardner, J. M., and D. M. Fambrough (1979) Acetylcholine receptor degradation measured by density labeling: Effects of cholinergic ligands and evidence against recycling. Cell 16: 661-674.

Halvorsen, S. W., and D. K. Berg (1986a) Identification of a nicotinic acetylcholine receptor on neurons using an $\alpha$-neurotoxin that blocks receptor function. J. Neurosci. 6: 3405-3412.

Halvorsen, S. W., and D. K. Berg (1986b) Active site subunits of a neuronal acetylcholine receptor examined by cross-linking with an alpha-neurotoxin. Soc. Neurosci. Abstr. 12: 147.

Halvorsen, S. W., and D. K. Berg (1987) Affinity labeling of neuronal acetylcholine receptor subunits with an $\alpha$-neurotoxin that blocks receptor function. J. Neurosci. (in press).

Jacob, M. H., and D. K. Berg (1983) The ultrastructural localization of alpha-bungarotoxin binding sites in relation to synapses on chick ciliary ganglion neurons. J. Neurosci. 3: 260-271.

Jacob, M. H., D. K. Berg, and J. M. Lindstrom (1984) Shared antigenic determinant between the Electrophorus acetylcholine receptor and a synaptic component on chick ciliary ganglion neurons. Proc. Natl. Acad. Sci. USA 81: 3223-3227.

Jacob, M. H., J. M. Lindstrom, and D. K. Berg (1986) Surface and intracellular distribution of a putative neuronal nicotinic acetylcholine receptor. J. Cell Biol. 103: 205-214.

Liles, W. C., and N. M. Nathanson (1986) Regulation of neuronal muscarinic acetylcholine receptor number by protein glycosylation. J. Neurochem. 46: 89-95.

Loring, R. H., V. A. Chiappinelli, R. E. Zigmond, and J. B. Cohen (1984) Characterization of a snake venom neurotoxin which blocks nicotinic transmission in the avian ciliary ganglion. Neuroscience 11:989-999.

Loring, R. H., L. M. Dahm, and R. E. Zigmond (1985) Amino acid sequence of a neurotoxin that blocks neuronal nicotinic receptors and 
the localization of its binding sites in chick ciliary ganglion. Soc. Neurosci. Abstr. 11:92.

Loring, R. H., D. Andrews, W. Lane, and R. E. Zigmond (1986) Amino acid sequence of Toxin $F$, a snake venom toxin that blocks neuronal nicotinic receptors. Brain Res. 385: 30-37.

Margiotta, J. F., D. K. Berg, and V. E. Dionne (1987) The properties and regulation of functional acetylcholine receptors on chick ciliary ganglion neurons. J. Neurosci. (in press).

Merlie, J. P. (1984) Biogenesis of the acetylcholine receptor, a multisubunit integral membrane protein. Cell $36: 573-575$.

Merlie, J. P., and J. Lindstrom (1983) Assembly in vivo of mouse muscle acetylcholine receptor: Identification of an alpha subunit species that may be an assembly intermediate. Cell 34: 747-757.

Merlie, J. P., R. Sebbane, S. Tzartos, and J. Lindstrom (1982) Inhibition of glycosylation with tunicamycin blocks assembly of newly synthesized acetylcholine receptor subunits in muscle cells. J. Biol. Chem. 257: 2694-2701.

Messing, A., B. Bizzini, and N. K. Gonatas (1984) Concanavalin A inhibits nicotinic acetylcholine receptor function in cultured chick ciliary ganglion neurons. Brain Res. 303: 241-249.

Nishi, R., and D. K. Berg (1979) Survival and development of ciliary ganglion neurones grown alone in cell culture. Nature 277: 232-234.

Nishi, R., and D. K. Berg (1981) Two components from eye tissue that differentially stimulate the growth and development of ciliary ganglion neurons in cell culture. J. Neurosci. 1 : 505-513.

Olson, E. N., L. Glaser, J. P. Merlie, R. Sebanne, and J. Lindstrom (1983) Regulation of surface expression of acetylcholine receptors in response to serum and cell growth in the $\mathrm{BC}_{3} \mathrm{Hl}$ muscle cell line. $\mathrm{J}$. Biol. Chem. 258: 13946-13953.

Pestronk, A. (1985) Intracellular acetylcholine receptors in skeletal muscles of the adult rat. J. Neurosci. 5: 1111-1117.

Ravdin, P. M., and D. K. Berg (1979) Inhibition of neuronal acetylcholine sensitivity by alpha-toxins from Bungarus multicinctus venom. Proc. Natl. Acad. Sci. USA 76: 2072-2076.
Ravdin, P. M., R. M. Nitkin, and D. K. Berg (1981) Internalization of $\alpha$-bungarotoxin on neurons induced by a neurotoxin that blocks neuronal acetylcholine sensitivity. J. Neurosci. 1: 849-861.

Reed, B. C., G. V. Ronnett, and M. D. Lane (1981) Role of glycosylation and protein synthesis in insulin receptor metabolism by 3T3L1 mouse adipocytes. Proc. Natl. Acad. Sci. USA 78: 2908-2912.

Schmidt, J., S. Rossie, and W. A. Catterall (1985) A large intracellular pool of inactive Na channel alpha subunits in developing rat brain. Proc. Natl. Acad. Sci. USA 82: 4847-4851.

Smith, M. A., J. F. Margiotta, and D. K. Berg (1983) Differential regulation of acetylcholine sensitivity and $\alpha$-bungarotoxin-binding sites on ciliary ganglion neurons in cell culture. J. Neurosci. 3: 2395-2402.

Smith, M. A., J. Stollberg, J. M. Lindstrom, and D. K. Berg (1985) Characterization of a component in chick ciliary ganglia that crossreacts with monoclonal antibodies to muscle and electric organ acetylcholine receptor. J. Neurosci. 5: 2726-2731.

Smith, M. A., J. F. Margiotta, A. Franco, Jr., J. M. Lindstrom, and D. K. Berg (1986) Cholinergic modulation of an acetylcholine receptorlike antigen on the surface of chick ciliary ganglion neurons in cell culture. J. Neurosci. 6: 946-953.

Stollberg, J. (1985) Characterization of a putative acetylcholine receptor in chick ciliary ganglion neurons. Doctoral dissertation, University of California, San Diego.

Stollberg, J., P. J. Whiting, J. M. Lindstrom, and D. K. Berg (1986) Functional blockade of neuronal acetylcholine receptors by antisera to a putative receptor from brain. Brain Res. 378: 179-182.

Tzartos, S. J., M. E. Seybold, and J. M. Lindstrom (1982) Specificities of antibodies to acetylcholine receptors in sera from myasthenia gravis patients measured by monoclonal antibodies. Proc. Natl. Acad. Sci. USA 79: $188-192$.

Whiting, P. J., and J. Lindstrom (1986) Purification and characterization of an acetylcholine receptor from chick brain. Biochemistry 25: 2082-2093. 